\title{
Measuring GNSS ionospheric total electron content at Concordia, and application to L-band radiometers
}

\author{
Vincenzo Romano ${ }^{1,{ }^{\star}}$, Giovanni Macelloni ${ }^{2}$, Luca Spogli ${ }^{1}$, Marco Brogioni ${ }^{2}$, \\ Giuditta Marinaro ${ }^{1}$, Cathryn N. Mitchell ${ }^{3}$ \\ ${ }^{1}$ Istituto Nazionale di Geofisica e Vulcanologia, Sezione Roma 2, Rome, Italy \\ ${ }^{2}$ Istituto di Fisica Applicata 'Nello Carrara' (IFAC-CNR), Sesto Fiorentino (Florence), Italy \\ ${ }^{3}$ University of Bath, Electronic and Electrical Engineering, Bath, United Kingdom
}

\author{
Article history \\ Received October 22, 2012; accepted March 27, 2013. \\ Subject classification: \\ Total electron content, Antarctica, GNSS, GPS, Faraday rotation, Ionosphere.
}

\begin{abstract}
In the framework of the project BIS - Bipolar Ionospheric Scintillation and Total Electron Content Monitoring, the ISACCO-DMCO and ISACCO-DMC1 permanent monitoring stations were installed in 2008. The principal scope of the stations is to measure the ionospheric total electron content (TEC) and to monitor the ionospheric scintillations, using high-sampling-frequency global positioning system (GPS) ionospheric scintillation and TEC monitor (GISTM) receivers. The disturbances that the ionosphere can induce on the electromagnetic signals emitted by the Global Navigation Satellite System constellations are due to the presence of electron density anomalies in the ionosphere, which are particularly frequent at high latitudes, where the upper atmosphere is highly sensitive to perturbations coming from outer space. With the development of present and future low-frequency space-borne microwave missions (e.g., Soil Moisture and Ocean Salinity [SMOS], Aquarius, and Soil Moisture Active Passive missions), there is an increasing need to estimate the effects of the ionosphere on the propagation of electromagnetic waves that affects satellite measurements. As an example, how the TEC data collected at Concordia station are useful for the calibration of the European Space Agency SMOS data within the framework of an experiment promoted by the European Space Agency (known as DOMEX) will be discussed. The present report shows the ability of the GISTM station to monitor ionospheric scintillation and TEC, which indicates that only the use of continuous GPS measurements can provide accurate information on TEC variability, which is necessary for continuous calibration of satellite data.
\end{abstract}

\section{Introduction}

The disturbances that the ionosphere can induce on the electromagnetic signals emitted by the Global Navigation Satellite System (GNSS) constellations are due to the presence of electron density anomalies in the ionosphere, which are particularly frequent at high latitudes where the upper atmosphere is highly sensitive to perturbations coming from outer space. Under disturbed conditions, the ionosphere can show 'patches' of high electron concentrations that can strongly jeopardize the satellite signals received at the ground [see, e.g., Yeh and Liu 1982, Wernik et al. 2003]. This is the main reason why scintillation monitoring has a central role in the development of forecasting tools within the space weather activities that are addressed to navigational and positioning systems [see, e.g., Fisher and Kunches 2011, Committee on the Societal and Economic Impacts of Severe Space Weather Events 2008].

The principal scope of the project BIS - Bipolar Ionospheric Scintillation and Total Electron Content Monitoring is to measure the ionospheric total electron content (TEC) and to monitor the ionospheric scintillations using suitably modified global positioning system (GPS) receivers. In the framework of this project, in January 2008 and December 2009, two GPS ionospheric scintillation and TEC monitor (GISTM) permanent stations were installed: ISACCO-DMC0 (latitude, $75.1001^{\circ} \mathrm{S}$; longitude $123.333^{\circ} \mathrm{E} ; 3280 \mathrm{~m}$ a.s.l.) and ISACCODMC1 (latitude, $75.106^{\circ} \mathrm{S}$; longitude, $123.305^{\circ} \mathrm{E} ; 3270$ $\mathrm{m}$ a.s.1.), respectively. Figure 1 shows the locations of the ISACCO receivers that were installed in Antarctica in the framework of the BIS project: two receivers at Concordia station, and one receiver at Mario Zucchelli station. The ISACCO-DMC0 and DMC1 stations enlarged the GNSS Research and Application for Polar Environment (GRAPE; http:/ / grape.scar.org/) scintillation and TEC receiver network, to cover the lack of experimental observations at the time. Such a network allows unprecedented observation of the polar ionosphere, with extended auroral and polar coverage, making it possible to map features from mid-latitudes through to polar latitudes, and to study the associated ionospheric processes. 


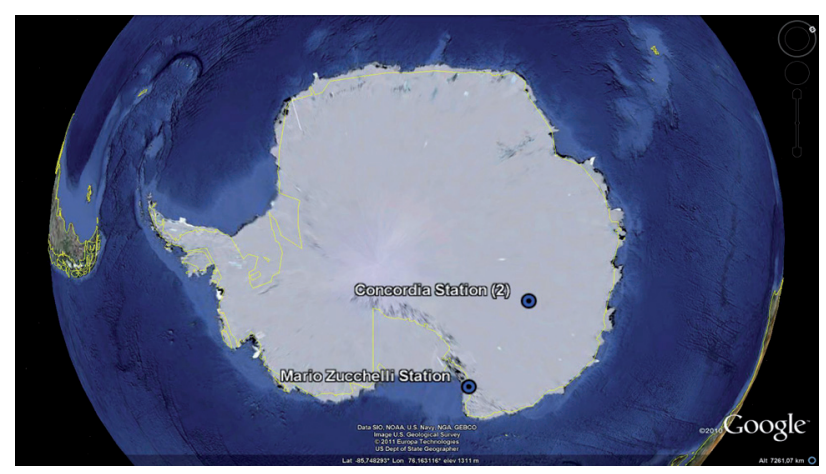

Figure 1. Location of the ISACCO stations in Antarctica, with two receivers at Concordia station and one receiver at Mario Zucchelli station.

Ionospheric parameter determination from highfrequency receivers is useful, not only for continuous monitoring of the polar ionosphere, but also as a possible application of TEC measurements at the DomeC site. In particular, in this report, the estimate of the effects of the ionosphere on the propagation of a lowfrequency microwave space-borne radiometer is presented. The choice of the Dome-C area was because within the framework of the European Space Agency Soil Moisture and Ocean Salinity (SMOS) calibration and validation activities [Kerr et al. 2010], it has been established that the observation of external independent targets, the characteristics of which are unrelated to the instrument on board the SMOS satellite, represents an attractive opportunity for the calibration procedure. Apart from stable ocean areas, the East Antarctic Plateau, and in particular the area near the Italian-French base of Concordia, appears to be par- ticularly suitable for this purpose [Macelloni et al. 2006]. Moreover, to correctly interpret the space-borne data, a precise estimation of the Faraday effect is also required. Indeed, when microwave radiation from the Earth surface propagates through the ionosphere, polarized field components are rotated by an angle, the Faraday rotation angle, the value of which depends on the geomagnetic field and ionosphere electronic content along the electromagnetic path. Space-borne radiometers typically measure the brightness temperature at vertical and horizontal polarizations (Tbv, Tbh, respectively), and therefore it is important to know how much these measured values differ from the actual values of the $\mathrm{Tb}$ of the emitting surface, and how this difference can vary over time. Such knowledge is particularly important for absolute calibration of the instruments placed on satellite platforms, as it allows properly correcting measured values.

It should be noted that several studies have been devoted to estimation of the impact of Faraday rotation on microwave remote sensing [Le Vine 2000, Yueh 2000, Abraham and Le Vine 2004, Freeman 2004, Meissner and Wentz 2006, ], and these have used the International Geomagnetic Reference Field (http: / / www. ngdc.noaa.gov/IAGA/vmod/igrf.html) and International Reference Ionosphere (http: / IRI.gsfc.nasa.gov/) models as sources of geomagnetic field and TEC data, respectively. Whereas these models work relatively well at a global scale, they are less accurate at the poles, due to the smaller amounts of long-term and continuous data. In this report, it is demonstrated that the acquisition of

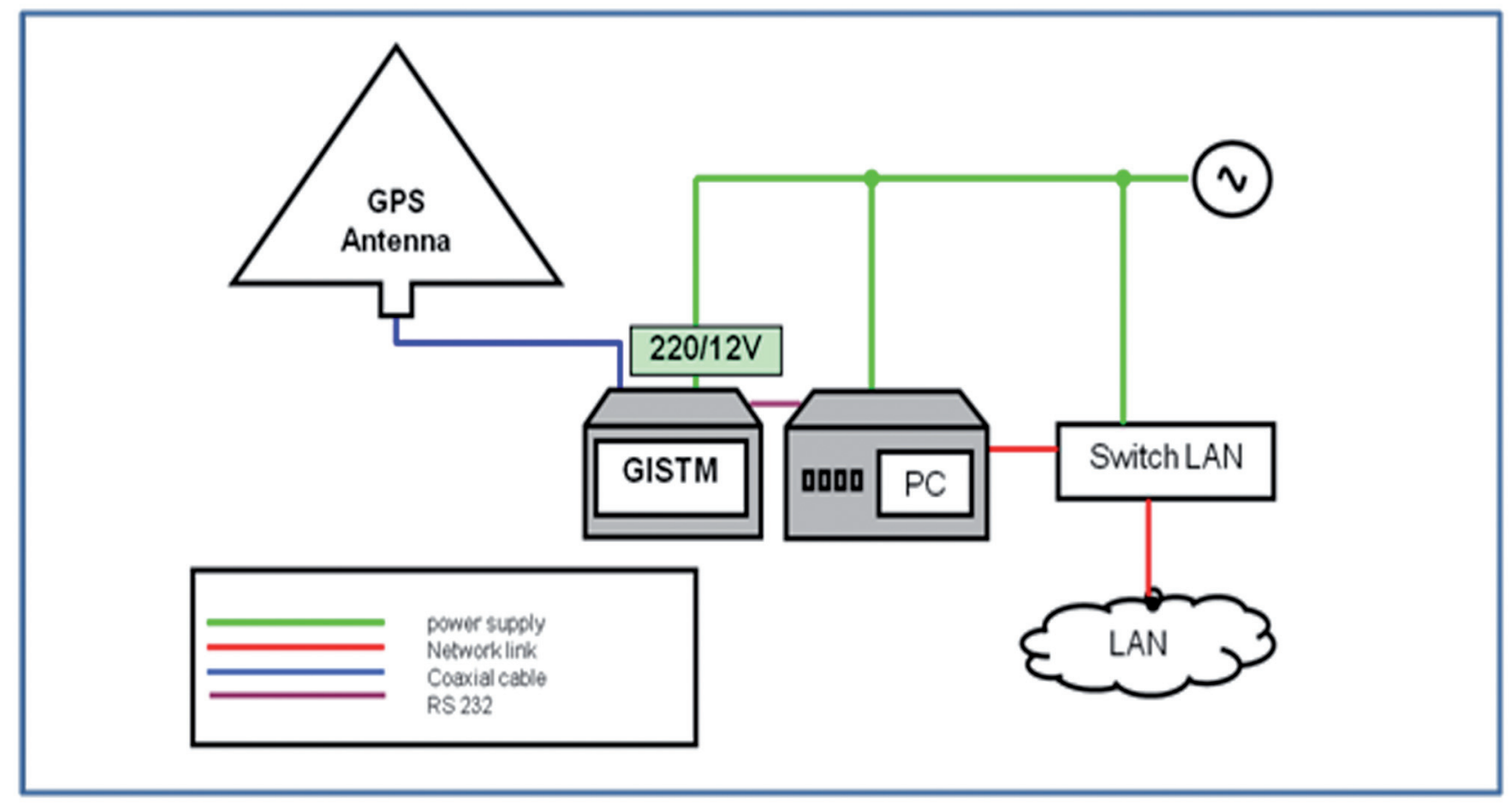

Figure 2. The ISACCO-DMC0 and DMC1 station block diagram. 

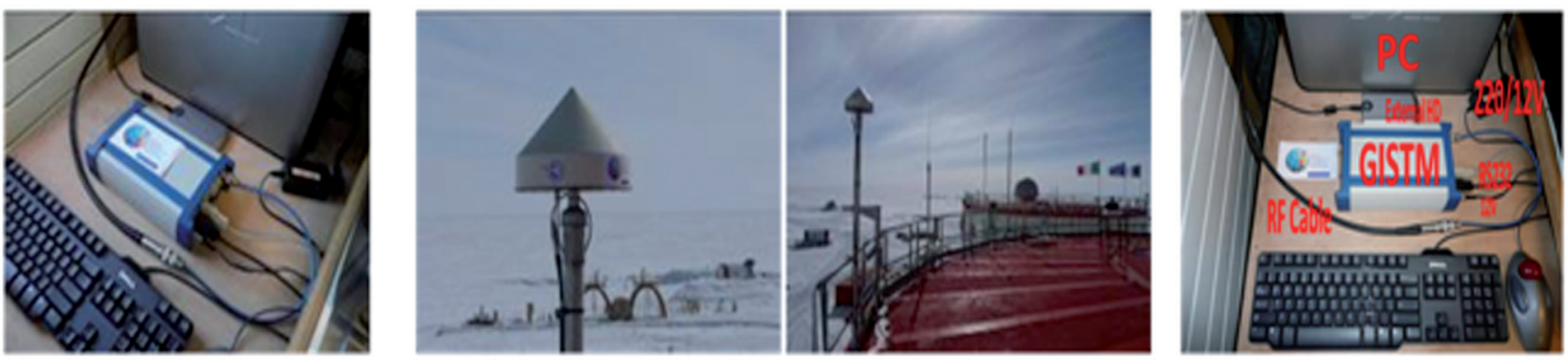

Figure 3. The ISACCO-DMC0 station installation (latitude, $75.1001^{\circ} \mathrm{S}$; longitude, $123.333^{\circ} \mathrm{E}, 3280 \mathrm{~m}$ a.s.l.).

real TEC data improves the estimation of the Faraday rotation and thus corrects the measured $\mathrm{Tb}$ values.

\section{Data and methods}

Each experimental station at Dome-C, a block diagram of which is illustrated in Figure 2, has a NovAtel OEM4 dual-frequency receiver with special firmware, which comprises the major component of a GPS signal monitor; this receiver is specifically configured to measure amplitude and phase scintillation from L1 frequency GPS signals, and ionospheric TEC from the L1 and L2 frequency GPS signals. Software is included in the GISTM to automatically compute and log the amplitude scintillation index, $S_{4}$, and the phase scintillation index, $\sigma_{\Phi}$, computed over 1, 3, 10, 30 and 60 s. In addition, the TEC and the TEC rates of change are both logged every $15 \mathrm{~s}$. Phase and amplitude data are either in the raw form or are detrended (to remove systematic variations), and these are also logged at $50 \mathrm{~Hz}$. The GISTM receivers can also compute signal quality parameters, like the carrier-to-noise ratio of both $\mathrm{L} 1$ and L2, and the code carrier standard deviation [Van Dierendock et al. 1993]. All scintillation and TEC data are stored locally and are available on the electronic space weather upper atmosphere (eSWua) database hosted by the Istituto Nazionale di Geofisica e Vulcanologia (INGV) [Romano et al. 2008] (http://www.eswua.ingv.it). Some pictures of the installation of the DMC 0 and DMC1 stations are given in Figure 3 and Figure 4, respectively.

In this study, we analyze vertical (v)TEC data acquired at the ISACCO-DMC0 station over three years, from January 2008 to December 2010. These data have very few gaps, and the percentage of total days of data available in each year is above $97.5 \%$, as summarized in Table 1. Vertical TEC (vTEC) values are obtained by projecting the slant (s)TEC directly measured by the GISTM receiver on the VTEC at the ionospheric piercing point (IPP), accordingly to the following formula:

$$
\mathrm{vTEC}=\operatorname{sTEC} / \mathrm{F}\left(\alpha_{\text {elev }}\right)
$$

where $\alpha_{\text {elev }}$ is the elevation angle from the receiver to the selected satellite, and $F\left(\alpha_{\text {elev }}\right)$ is the obliquity factor,

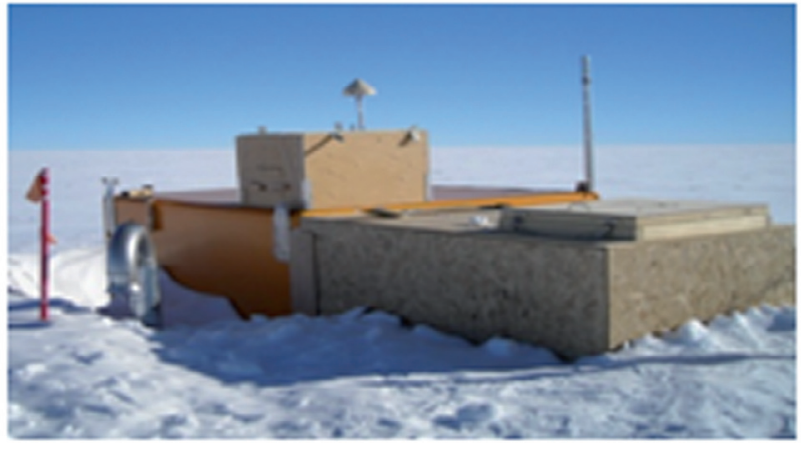

Figure 4. The ISACCO-DMC1 station installation site (latitude, $75.106^{\circ} \mathrm{S}$; longitude, $123.305^{\circ} \mathrm{E} ; 3270 \mathrm{~m}$ a.s.1.).

as defined by [Mannucci et al. 1993]:

$$
F\left(\alpha_{\text {elev }}\right)=\frac{1}{\sqrt{1-\left(\frac{R_{e} \cos \alpha_{\text {elev }}}{R_{e}+H_{I P P}}\right)^{2}}}
$$

where $R_{e}$ is the Earth radius, and $H_{I P P}$ is the height of the IPP, which is assumed to be $400 \mathrm{~km}$. As GISTM outputs a sTEC value every $15 \mathrm{~s}$, we consider the average of the four values in $1 \mathrm{~min}$ to calculate the corresponding vTEC. The sTEC was calibrated using the bias value furnished by the receiver firmware designer [Van Dierendock et al. 1993]. The TEC is a key parameter for characterizing ionospheric variability, and its estimation from GPS measurements is nowadays an internationally acknowledged method for operational monitoring of the ionospheric state. The data analysis shown here mainly relies on the Ground Based Scintillation Climatology (GBSC), as described by Spogli et al. [2009, 2010] and Alfonsi et al. [2011]. GBSC produces maps of mean values and standard deviations (SD) of different quantities measured by the GISTM receiver, such as the vTEC, and the carrier-to-noise ratio of the L1 frequency

\begin{tabular}{cc}
\hline Year & \% \\
\hline 2008 & 97.5 \\
2009 & 100 \\
2010 & 98.1 \\
\hline
\end{tabular}

Table 1. Percentage of days of available ISACCO-DMC0 data. 

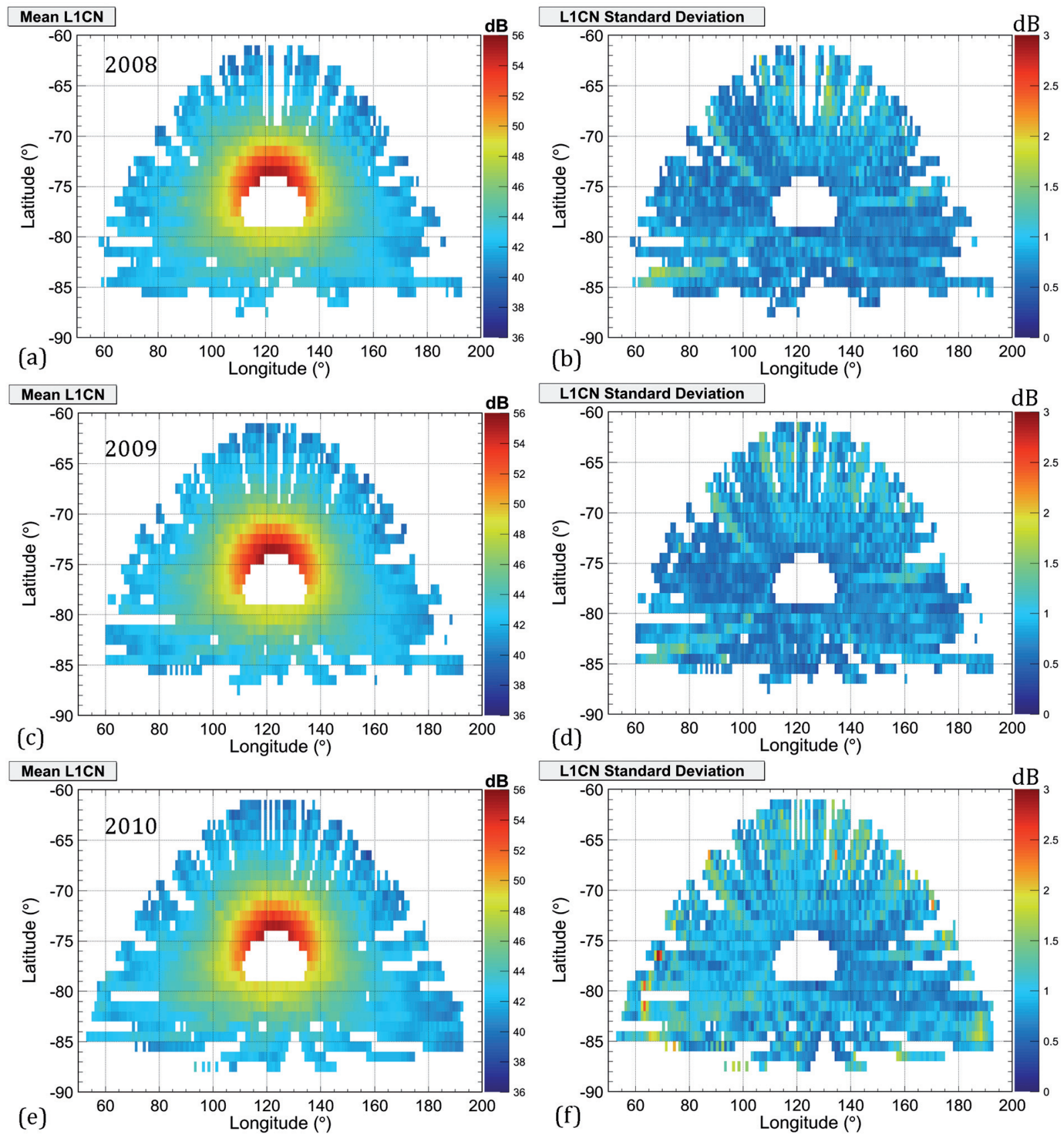

Figure 5. Maps of the L1C/N mean (left column) and SD (right column) in geographic coordinates for the three years of data: 2008 (a, b), 2009 (c, d) and 2010 (e, f).

$(\mathrm{L} 1 \mathrm{C} / \mathrm{N}) . \mathrm{L} 1 \mathrm{C} / \mathrm{N}$ is sensitive to possible sources of interference from other electromagnetic sources in proximity to the field of view of the GISTM antenna. In particular, the maps of L1C/N mean and SD can identify specific bins in which the signal quality experiences unexpected behavior. The maps of $\mathrm{L} 1 \mathrm{C} / \mathrm{N}$ allow the characterizing of the station by determining possible sources of signal distortions that affect the TEC measurements.

The maps are presented here in terms of the geographic coordinates of the IPP, and the bin size was chosen to be $1^{\circ}$ latitude $\times 1^{\circ}$ longitude. Maps of L1C/ $\mathrm{N}$ are produced for each year, while the vTEC maps are only produced on a tri-monthly basis, to catch the seasonality of the ionospheric variability. To remove the contribution of bins with poor statistics, which could affect the occurrence estimation, the selected accuracy is set at 5\% (see Taylor [1997] and Spogli et al. [2009] for application to the GBSC).

\section{Results}

Figure 5 shows the maps of the L1C/N mean (left column) and SD (right column) in geographic coordinates for the three years of data, as 2008 (Figure 5a, b), 2009 (Figure 5c, d) and 2010 (Figure 5e, f). Both the L1C/ $\mathrm{N}$ mean and SD maps show that the signal quality is good in each year, with it ranging from $36 \mathrm{~dB}$ to 56 $\mathrm{dB}$, with mean values and SD generally below $2 \mathrm{~dB}$, except for a very few bins in the 2010 maps (Figure $5 \mathrm{f}$ ). In 
general, in 2010, the L1C / N SD was larger than in 2008 and 2009, and this is likely to be due to interference from a parabolic antenna installed on the roof of the Concordia Station in early 2010 . The area most affected by the degradation of the signal quality is the latitudinal sector between about $60^{\circ} \mathrm{E}$ and $80^{\circ} \mathrm{E}$, and in the latitudinal sector ranging from about $-85^{\circ} \mathrm{N}$ to $-75^{\circ} \mathrm{N}$.

Figure 6 shows the map of the L1C/N SD in geographic coordinates for 2010, superimposed by a black curve that represents the IPP of the satellite signals with elevation angles of $20^{\circ}$, which is the typical threshold to remove multipath from observations. The signal degradation due to the parabolic antenna is removed by applying this filtering.

Figure 7 shows the maps of the vTEC in geographic coordinates of 2008 (top row), 2009 (middle row) and 2010 (bottom row). Each map refers to a three month period, which is representative of the seasonal variability: January to March (summer), April to June (fall), July to September (winter) and October to December (spring). The vTEC values range from a few TEC units (TECu) up to about 22 TECu during the austral summer and spring. During the austral night, the mean values of vTEC are generally below $10 \mathrm{TECu}$. To catch the seasonality in detail, a month-by-month time profile of vTEC is also presented. Thus Figure 8 shows the monthly variation of the mean vTEC over station ISACCO-DMC0, measured by removing the observations at elevation angles below $20^{\circ}$. This threshold in the elevation allows the removal of the contributions due to degradation of the signal induced by multipath and reflections, as suggest by Figure 6 . The SD of the monthly distribution of the vTEC is here indicated as the error bars. Figure 8 shows the variability that is induced by solar radiation and equinoxes, with relative maxima between February $(2008,2009)$ and March $(2010)$, and in October (2008), November (2009) and December (2010). These last peaks are due to the combination of the maximum solar flux during the austral summer and the equinoctial configuration that allows the penetration of solar wind particles from the magnetosphere into the ionosphere. This penetration gives rise to enhanced electron density that drifts across the polar cap. The time profile of the vTEC suggests also that the vTEC was lower in 2009, with respect to 2008 and 2010, with it being maximum in 2010. This reflects the fact that during 2009 the descending phase of the past solar cycle reached its minimum, and then started to increase through 2010.

\section{Application to L-band radiometers}

The Faraday rotation can be expressed by an integral of the geomagnetic field and the electron density along the satellite line of sight [Meissner 2006], as

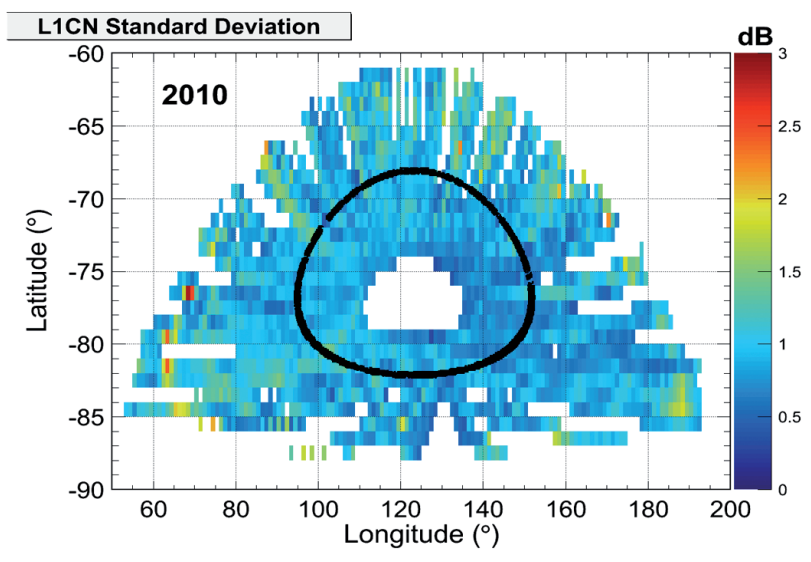

Figure 6. Map of the L1C/N SD in geographic coordinates for 2010. The black curve represents the IPP of the satellite signals with elevation angles of $20^{\circ}$.

follows:

where:

$$
\varphi_{F}=\frac{135 \cdot 10^{-18}}{\nu^{2}} \int_{0}^{l} n_{e} \vec{B}_{g e o} \cdot d \vec{s}
$$

$$
\begin{aligned}
& \left.\varphi_{F}=\text { Faraday rotation angle (clockwise } \varphi_{F}>0\right)(\text { de- } \\
& \text { grees) } \\
& \nu=\text { frequency }(\mathrm{GHz}) \\
& \vec{B}_{\text {geo }}=\text { geomagnetic field vector (Tesla) } \\
& n_{e}=\text { electron density profile as a function of lati- } \\
& \text { tude, longitude and altitude }\left(\mathrm{m}^{-3}\right) \\
& l=\text { position of the satellite in space (km a.s.l.). }
\end{aligned}
$$

Considering that the electron density has a peak at an altitude of ca. $400 \mathrm{~km}$ a.s.l. (corresponding to the peak of the F2 layer of the ionosphere), and that the TEC measurements give an integrated value of the electron content of the atmosphere (not a profile), a common approximation is to assume that all of the electrons are concentrated in the F2 layer [Davis 1990, Liu et al. 2005]. Thus:

$$
n_{e}(h, \text { Lat }, \text { Lon }) \cong s T E C \cdot \delta(h-400 \mathrm{~km})
$$

where $d$ is the Dirac delta function and $s T E C$ (i.e., the slant TEC) is given by:

$$
s T E C \cong \int_{0}^{l} n_{e}(h, \text { Lat }, \text { Lon }) d l
$$

The GPS techniques [Sardon et al. 1994] give a measurement of the sTEC in the ionosphere of up to ca. $20,000 \mathrm{~km}$; i.e., the height of the navigation satellites. As the altitude of the SMOS satellite orbit is ca. $700 \mathrm{~km}$, the sTEC computed by the GPS techniques also contains a residual sTEC value above the SMOS satellite altitude (i.e., from 700 to $20,000 \mathrm{~km}$ ), which must not be taken into account in the calculation of the Faraday rotation. The residual sTEC value depends on the ionosphere and plasmasphere conditions, and 

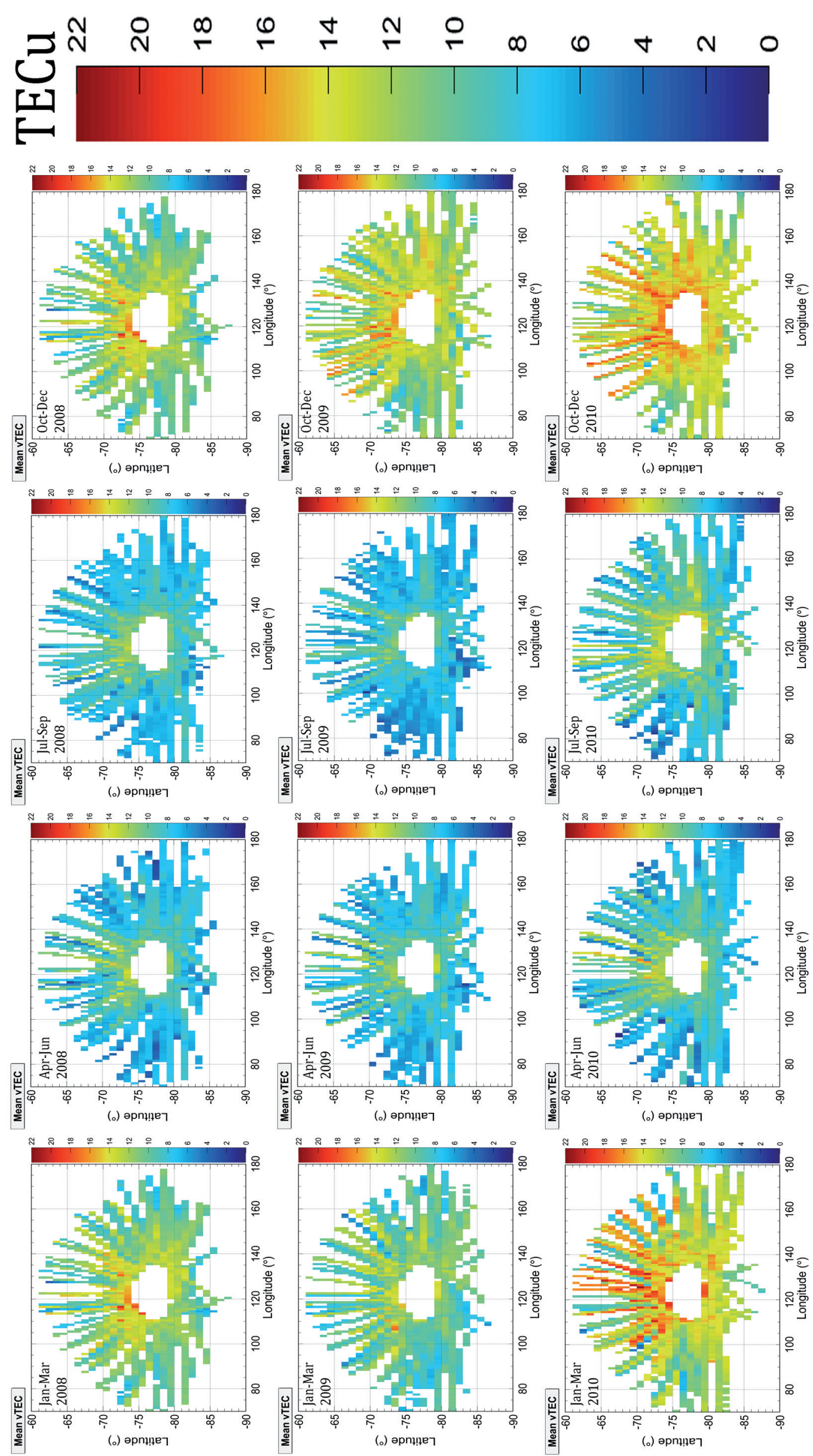

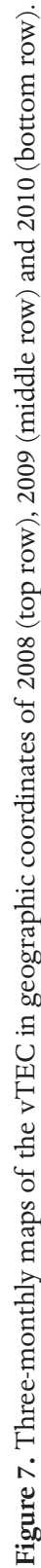




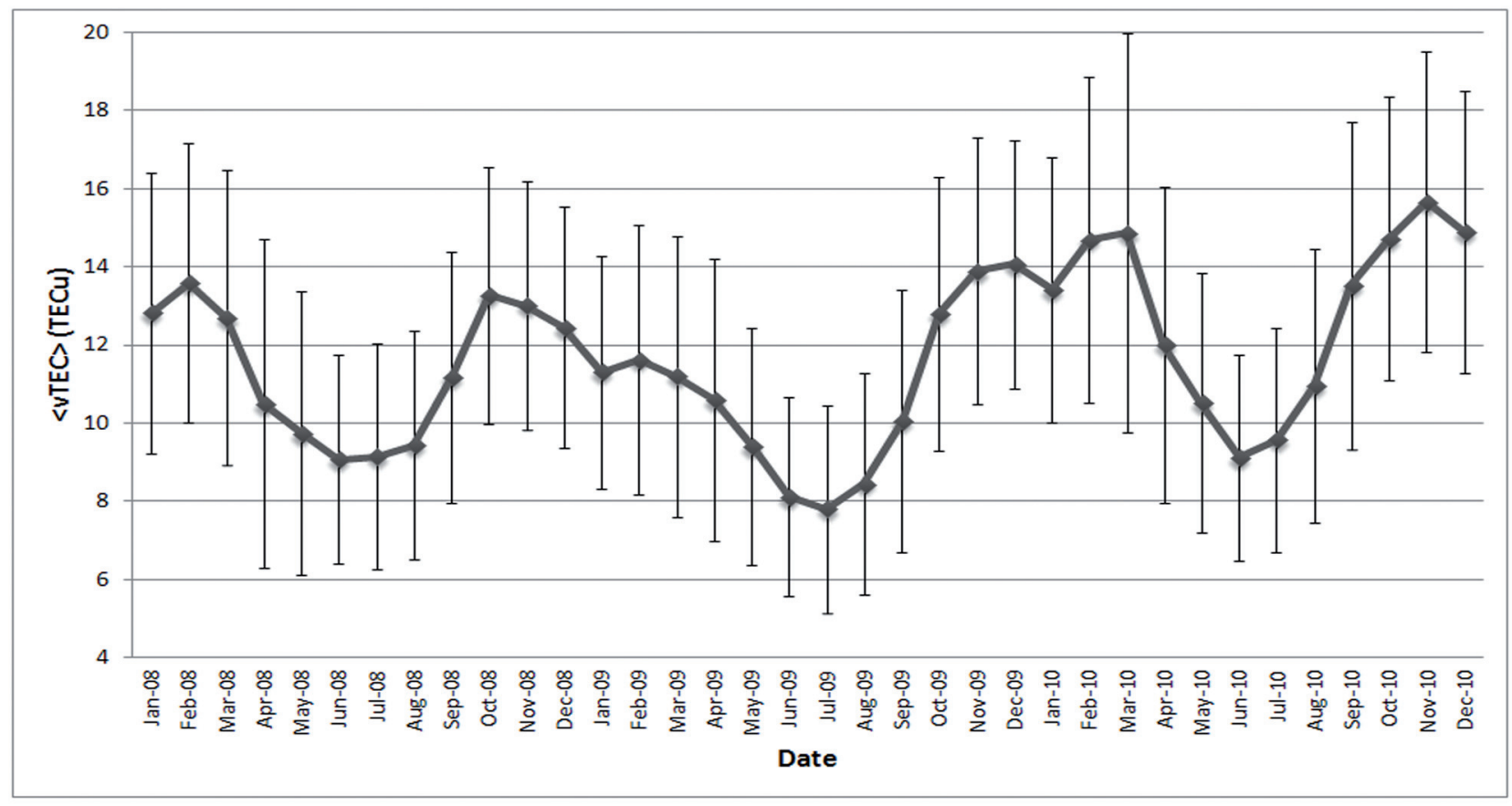

Figure 8. Mean monthly variation of the vTEC over the whole field of view of the ISACCO-DMC0 station for the three years considered. The error bars show the SD of the distribution.

whereas it is in general lower than $10 \%$ of the total sTEC, in some cases it can reach a value of $15 \%$ of the total [Webb and Essex 1997]. Nevertheless, we must consider that the value of the geomagnetic field decreases very rapidly when the distance from the Earth increases. For instance, using the International Geomagnetic Reference Field (IGRF)-11, we determined the values of the total intensity $F$ of the geomagnetic field over the Concordia stations, and determined $F$ as $52511 \mathrm{nT}$ at $400 \mathrm{~km}, 39982 \mathrm{nT}$ at $1000 \mathrm{~km}$, and 26769 $\mathrm{nT}$ at $2000 \mathrm{~km}$, which thus results in an impact on the residual sTEC values on the Faraday rotation that is much lower than $10 \%$. Suggested procedures for correcting the residual value using ionospheric models (i.e. IRI, IGS, NeQuick) were reported by Floury [2007]. Because the purpose of the present study is the estimation of Faraday rotation using real sTEC data we prefer to not use these models and disregard the residual value. It should be noted that in this case, the Faraday rotation is overestimated.

By inserting Equations (2) and (3) into Equation (1), the final simplified expression for the Faraday rotation angle is as follows:

$$
\varphi_{F}=1.355 \frac{10^{4}}{v^{2}} \cdot s T E C \cdot B_{0} \cos (\alpha)
$$

where $B_{o}$ is the geomagnetic field intensity (Tesla) at $400 \mathrm{~km}$ in altitude, and a is the angle between the line of sight and the direction of the geomagnetic field (degrees).

It can be demonstrated [Tsang 1991, Yueh 2000] that the $\mathrm{Tb}$ measured by satellite in horizontal and vertical polarization is related to the Faraday rotation through the following relationships:

$$
\begin{aligned}
& T_{V a}=T_{V}-\Delta T_{b}=T_{V}-\left[Q \sin ^{2} \varphi_{F}-\frac{U}{2} \cos 2 \varphi_{F}\right] \\
& T_{H a}=T_{H}-\Delta T_{b}=T_{H}-\left[Q \sin ^{2} \varphi_{F}-\frac{U}{2} \cos 2 \varphi_{F}\right]
\end{aligned}
$$

where $Q$ and $U$ are the second and the third Stokes parameters, respectively. For isotropic surfaces, $U$ is zero and reaches a value of tenths of a Kelvin at the L-band for ocean surfaces; in this case, it is possible to disregard this term. Hence, the effects of the Faraday rotation on the measured brightness temperature can be expressed by:

$$
\Delta T_{b} \cong Q \sin ^{2} \varphi_{F}=\left(T_{V}-T_{H}\right) \sin ^{2} \varphi_{F}
$$

To quantify the impact of real TEC measurements, instead of the use of global ionospheric models, a systematic analysis over the Dome-C area is presented below.

To estimate how the Faraday rotation can affect the satellite measurements acquired over the Dome-C area, we have to consider the positions of the SMOS satellite and Concordia station, and the observation of four lines of sight with respect to the direction of the geomagnetic field. In particular, we estimate the Faraday rotation along four different directions, which are expressed in geographic coordinates using the real TEC data shown in the previous section, and in four different periods of 2008 (January, March, June, September), to allow for the seasonal variability of the ionosphere characteristics. In particular, the average 

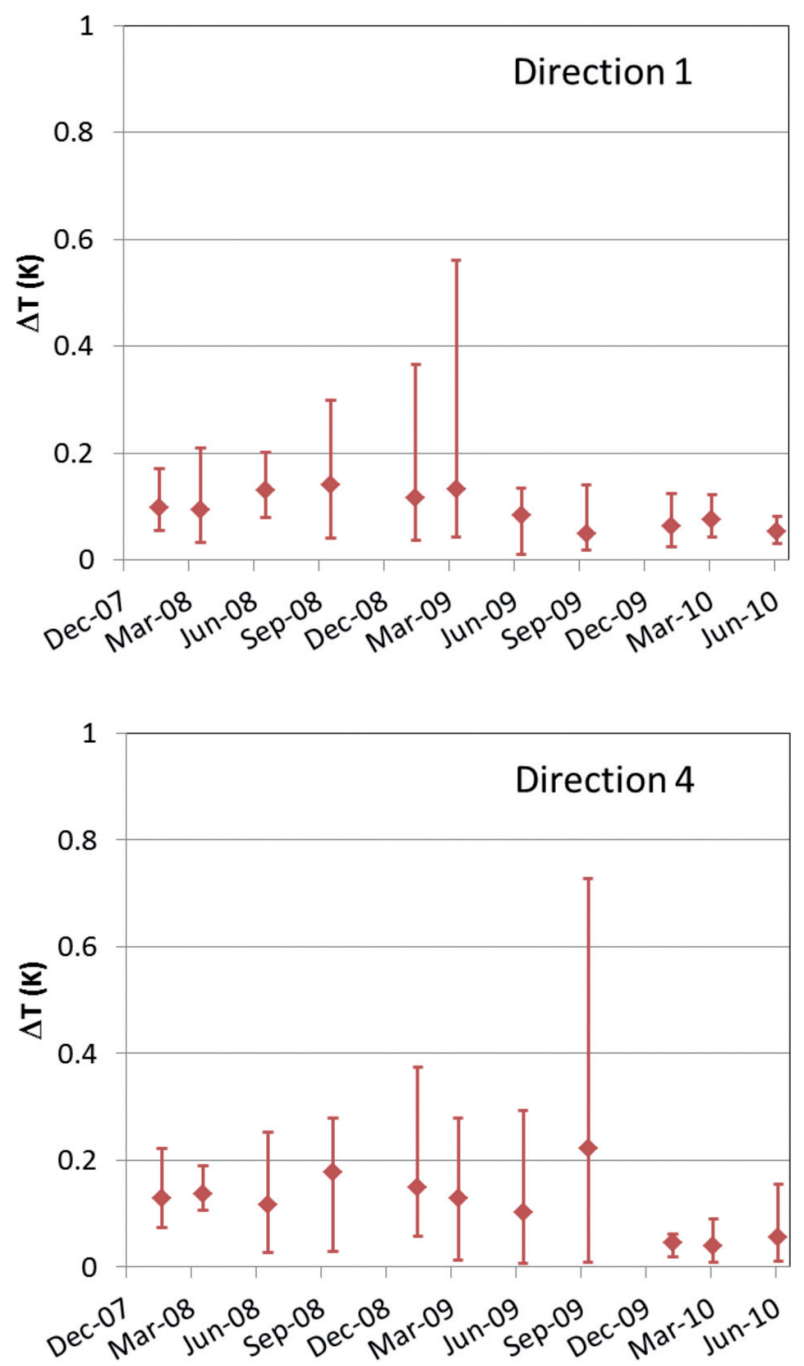

Figure 9. Computed DTb as a function of time for directions 1 and 4 for measurements performed with an observation angle of $42.5^{\circ}$.
sTEC value is computed using the following steps:

- We consider the area of the nominal pixel of the SMOS satellite $(40 \mathrm{~km} \times 40 \mathrm{~km})$ centered over the Dome-C station;

- We compute the satellite position along each direction considered in the study for a SMOS satellite observation angle of $42^{\circ}$, which is the angle selected to cover the whole swathe and used for the browse product of the SMOS satellite;

- We calculate the beamwidth of an equivalent antenna that would image the pixel from the four different positions;

- Lastly, since the F2 layer is approximately in the middle of the line of sight, we used the sTEC measurements contained in the four different beams to obtain average, maximum, minimum and SD values of the sTEC computed over a week.

The sTEC value obtained is then used for the calculation of the Faraday rotation according to Equation (6), and finally $\Delta \mathrm{Tb}$ from Equation (8). In this study, the value of the $Q=\left(T_{V}-T_{H}\right)$ difference was obtained from the measurements of the DOMEX-2 experiment that was carried out in Antarctica in 2009-2010 [Macelloni et al. 2009]. At the incident angle of $42^{\circ}$, which was considered for the computation, the measured value of the second Stokes parameter $Q$ was ca. $20 \mathrm{~K}$.

The results obtained for two directions are shown in Figure 9. It is possible to see that the mean brightness temperature variation is quite stable, and its value is ca. $0.1 \pm 0.04 \mathrm{~K}$ for all of the period and directions considered. Usually, the maximum value of $\Delta \mathrm{Tb}$ slightly

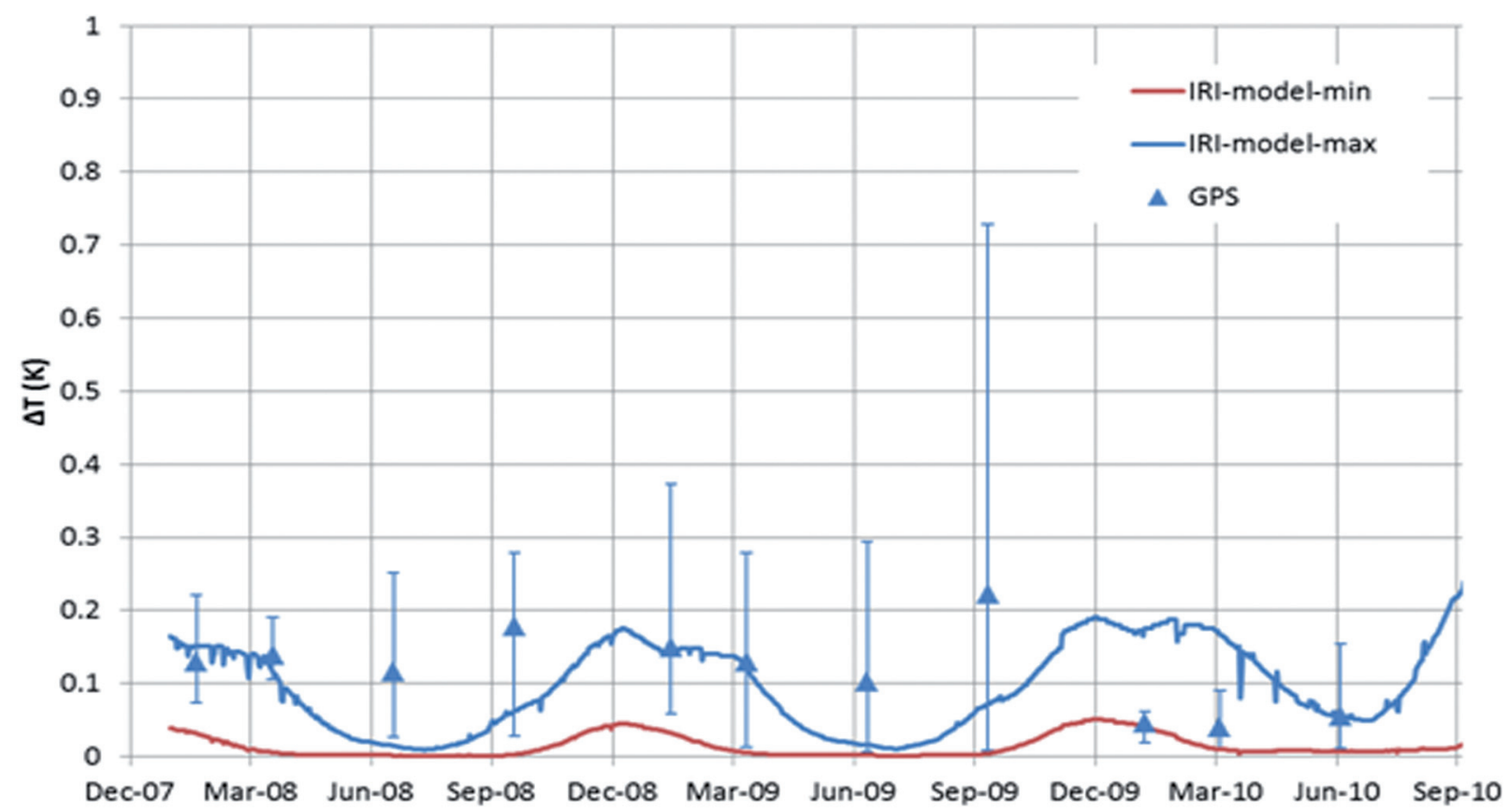

Figure 10. $\Delta \mathrm{T}$ variations over direction 4 computed using the sTEC data derived from the GPS data (triangles) or the IRI model (red, blue lines). 
exceeds $0.2 \mathrm{~K}$, although it can reach values higher than $0.5 \mathrm{~K}$ independent of the season and/or the observation direction. It should also be noted that the minimum values of $\Delta \mathrm{Tb}$ were close to the mean values; this means that in the considered period, the ionosphere was usually stable and that maximum perturbations are not common. It is worth noting that the sTEC measurements were performed during the quietest period of the solar activity in decades, and that higher values will be reached during the period of the SMOS mission, due to high solar activity periods or events such as coronal mass ejections.

To estimate the potential benefit of using in-situ GPS measurements instead of the TEC model, the $\triangle \mathrm{Tb}$ for direction 4 using TEC data or the model is shown in Figure 10. We can observe that whereas the model can correctly predict the average $\Delta \mathrm{Tb}$ values, it cannot simulate the fluctuations, and in particular the peak events. This can lead to an underestimation of the $\Delta \mathrm{Tb}$, which can exceed $0.5 \mathrm{~K}$. The computation performed for the other directions showed similar results.

\section{Conclusions}

In the framework of the BIS project, two ISACCO permanent stations have been active since 2008, to monitor the ionospheric TEC and the ionospheric scintillations. Both of these stations have data coverage with very few data gaps; in particular, for the the ISACCO DMC0 station, the percentage of total days of data available in each year is above $97.5 \%$. Signal quality was analyzed through the GBSC technique, and it is good for each year, ranging from $36 \mathrm{~dB}$ to $56 \mathrm{~dB}$ in mean values, with a SD generally below $2 \mathrm{~dB}$, except for a few sky sectors in 2010. In general, the L1C / N SD in 2010 is larger than in 2008 and 2009, and this appears to be due to interference from a parabolic antenna installed on the roof of the Concordia station in early 2010. The vTEC seasonality shows a range from a few TECu up to about 22 TECu during the austral summer and spring, while during the austral night, vTEC is generally below $10 \mathrm{TECu}$. The vTEC time profile also reflects the solar activity, as for 2009; i.e., the minimum of the past solar cycle, when it reached its minimum and then started to increase through 2010.

The vTEC measurements of the DMC0 receiver were applied to estimate the Faraday rotation, to quantify the impact of real measurements instead of the use of global ionospheric models in microwave low-frequency satellite measurements. In our case, the application of the brightness temperature $(\mathrm{Tb})$ acquired by the SMOS satellite to the measurements shows that the effects of the Faraday rotation are relatively stable and lead to an influence on the measured $\mathrm{Tb}$ of ca. 0.1 $\pm 0.04 \mathrm{~K}$ for all of the period and directions considered. By comparing the modeled and measured Faraday rotation, we observe that while the model can correctly predict the average $\Delta \mathrm{Tb}$ values, it cannot simulate the fluctuations, and in particular the peak events. In particular, the analysis performed demonstrates that $\Delta \mathrm{Tb}$ can be underestimated by more than $0.5 \mathrm{~K}$. It is difficult to evaluate whether this value is representative of the whole 11-year solar cycle, and the continuous acquisition of TEC data and ground radiometric data (i.e., the DOMEX-3 experiment) is recommended for the monitoring of the absolute performance of space-borne radiometers and the inter-calibration of the three L-band space-borne radiometric missions (the SMOS, Aquarius, and Soil Moisture Active Passive missions) during high solar activity periods.

Acknowledgements. This study was carried out with financial support from the European Space Agency and the Italian National Research Programme for Antarctica (PNRA). The present study was made possible by the joint French-Italian Concordia programme, which has established and runs the permanent stations at Dome C. Part of this study was carried out in the framework of the GRAPE SCAR Expert Group activities (www.grape.scar.org). The authors are grateful to the Italian-French logistic team at Concordia station for their kind assistance and for their maintenance of the experimental activities.

\section{References}

Abraham, S., and D.M. Le Vine (2004). Use of IRI to model the effect of ionosphere emission on Earth remote sensing at L-band, Adv. Space Res., 34, 2059-2066.

Alfonsi, L., L. Spogli, G. De Franceschi, V. Romano, M. Aquino, A. Dodson and C.N. Mitchell (2011). Bipolar climatology of GPS ionospheric scintillation at solar minimum, Radio Sci., 46, RS0D05; doi:10.102 9/2010RS004571.

Committee on the Societal and Economic Impacts of Severe Space Weather Events (2008). Severe Space Weather Events - Understanding Societal and Economic Impacts Workshop Report, ISBN 0-30912770-X.

Davis, K. (1990). Ionospheric Radio, London, Peregrinus, p. 276.

Fisher, G., and J. Kunches (2011). Building resilience of the global positioning system to space weather, Space Weather, 9, S12004; doi:10.1029/2011SW000718.

Floury, N. (2007). Estimation of Faraday rotation from auxiliary data, ESA Technical Note, TEC-EEP/2009. $437 / N F$.

Freeman, A., and S.S. Saatchi (2004). On the detection of Faraday rotation in linearly polarized L-band SAR backscatter signatures, Trans. on Geoscience and Remote Sensing, 42 (8), 1607-1616. 
Kerr, Y.H., P. Waldteufel, J-P. Wigneron, F. Cabot, J. Boutin, M-J. Escorihuela, N. Reul, C. Gruhier, S. Juglea, J. Font, S. Delwart, M.R. Drinkwater, A. Hahne, M. Martin-Neira and S. Mecklenburg (2010). The SMOS mission: a new tool for monitoring key elements of the global water cycle, Proc. IEEE, 9866698687; doi:10.1109/JPROC.2010.2043032.

Le Vine, D.M., and S. Abraham (2000). Faraday rotation and passive microwave remote sensing of soil moisture from space, In: P. Pampaloni and S. Paloscia (eds.), Microwave Radiometry and Remote Sensing of the Earth's Surface and Atmosphere, Utrecht/ Boston/Köln/Tokyo, 89-96.

Liu, Z., S. Skone, Y. Gao and A. Komjathy (2005). Ionospheric modeling using GPS data, GPS Sol., 9 (1), 6366; doi:10.1007/s10291-004-0129-z.

Macelloni, G., M. Brogioni, P. Pampaloni, A. Cagnati and M.R. Drinkwater (2006). DOMEX 2004: An experimental campaign at Dome-C Antarctica for the calibration of spaceborne low-frequency microwave radiometers, Geosci. Rem. Sens., IEEE Transact., 44, 2642-2653.

Macelloni, G., M. Brogioni, A. Crepaz, M. Drinkwater and J. Zaccaria (2009). DOMEX-2: L-band microwave emission measurements of the Antarctic Plateau, Geosci. Rem. Sens. Symposium, 2009 IEEE International, IGARSS, 2, II-1016-II-1019.

Mannucci, A.J., B.D. Wilson and C.D. Edwards (1993). A new method for monitoring the Earth ionosphere total electron content using the GPS global network, In: Proceedings of ION GPS-93, 1323-1332.

Meissner, T., and F.J. Wentz (2006). Polarization rotation and the third Stokes parameter: the effects of spacecraft attitude and Faraday rotation, Trans. Geosci. Rem. Sens., 44, 506-515.

Romano, V., S. Pau, M. Pezzopane, E. Zuccheretti, B. Zolesi, G. De Franceschi and S. Locatelli (2008). The Electronic Space Weather Upper Atmosphere (eSWua) project at INGV: advances and state of the art, Annales Geophysicae, 26, 345-351.

Sardon, E., A. Rius and N. Zarraoa (1994). Estimation of the transmitter and receiver differential biases and the ionospheric total electon content from global positioning system observations, Radio Sci. 29, 577.

Spogli, L., L. Alfonsi, G. De Franceschi, V. Romano, M.H.O. Aquino and A. Dodson (2009). Climatology of GPS ionospheric scintillations over high and midlatitude European regions, Annales Geophysicae, 27, 3429-3437.

Spogli, L., L. Alfonsi, G. De Franceschi, V. Romano, M. H. O. Aquino and A. Dodson (2010). Climatology of GNSS ionospheric scintillations at high and midlatitudes under different solar activity conditions, Il
Nuovo Cimento B, 5 / 6, 623-632; doi:10.1393/ncb/i 2010-10857-7.

Taylor, J.R. (1997). An Introduction to Error Analysis: The Study of Uncertainties in Physical Measurement, $2^{\text {nd }}$ ed., University Science Books, Sausalito, California.

Tsang, L. (1991). Polarimetric passive remote sensing of random discrete scatterers and rough surfaces, J. Electromag. Waves Appl., 5, 41-57.

Van Dierendonck, A.J., J. Klobuchar and Q. Hua (1993). Ionospheric scintillation monitoring using commercial single frequency $\mathrm{C} / \mathrm{A}$ code receivers, In: ION GPS-93 Proceedings of the Sixth International Technical Meeting of the Satellite Division of the Institute of Navigation (Salt Lake City, U.S.A.), 1333-1342.

Webb, P.A., and E.A. Essex (1997). A simple model of the ionosphere plasmasphere system, In: A. Kulessa, G. James, D. Bateman and M. Tobar (eds.), Proceedings of the Workshop on Applications of Radio Science, (WARS'97, Barossa Valley, Australia), 190-195.

Wernik, A.W., J.A. Secan and E.J. Fremouw (2003). Ionospheric irregularities and scintillation, Adv. Space Res., 31, 971-981.

Yeh, K.C., and C.H. Liu (1982). Radio wave scintillations in the ionosphere, Proceedings of the IEEE 70 (4), 324-360.

Yueh, S.H. (2000). Estimates of Faraday rotation with passive microwave polarimetry for microwave remote sensing of Earth surfaces, Trans. Geosci. Rem. Sens., 38, 2434-2438.

\footnotetext{
${ }^{\star}$ Corresponding author: Vincenzo Romano, Istituto Nazionale di Geofisica e Vulcanologia, Sezione Roma 2, Rome, Italy; email: vincenzo.romano@ingv.it.

C) 2013 by the Istituto Nazionale di Geofisica e Vulcanologia. All rights reserved.
} 